\title{
Editorial
}

\section{The value of retrospection, reflection and strong tools of analysis}

Asking distinguished European colleagues in the field of ICT in public administration to contribute in retrospective mode to a celebratory event and, from that, to write up their thoughts for this journal has proved a great success. Miriam Lips' collection of these essays, together with her own thoughtful contributions should prove of value to scholars working in this field, not least for the way in which these essays reveal the ebb and flow of dominant ideas that have shaped research during the 20 year period of the EGPA Study Group on ICT in Public Administration. One overarching theme that comes through this collection is that reflective retrospection has value not simply in enabling us to see where research and thinking has moved on but also in reminding us that, in moving on, valuable ideas and approaches to understanding can be lost.

As with so many contributions to this journal over the years of its publication, the call for more reflective approaches to planning, designing and implementing ICT 'solutions' in public administration is to be found in the final two contributions to this edition.

Fuat Alican's trenchant critique of Turkey's Information Society Strategy reveals how initiatives are taken on by Governments [in this case Turkey's government] that fail to adhere to well-researched design principles and that focus too much on the [usually] normative consumption end of public policy rather than on an empirically grounded understanding of capabilities on the production side of the design equation. Dramatically, but unfortunately from a Turkish government perspective, Alican concludes that "The end result is an unworkable project and a grand risk of failure".

Rony Medaglia, similarly to Fuat Alican, brings an important aspect of ICT in public administration 'down to earth'. In Medaglia's case the core concern is with the strong rhetoric surrounding forms of eparticipation and the need for better understanding and analytical tool making in this field as a prelude to more extensive uptake of such initiatives. Medaglia argues that from his evidence in Italy, e-participation is severely limited in its extent and depth and that this empirical fact strengthens rather than weakens the case for developing strong analytical tools in this field. Thus, whilst e-participation initiatives are largely restricted in Italy, at least to the provision of information and, to a small extent, public consultation, and whilst this dearth of activity can be largely explained by 'institutional constraints' on action, nonetheless "a standard analysis tool and a first application of it to a significant national case can ... foster the establishment of a common ground for research on the adoption of ICT for participation in local government".

\author{
J.A. Taylor \\ Editor in Chief \\ December, 2007
}

